\title{
A estrutura do Serviço Secreto na ditadura militar: a formação dos agentes secretos na Escola Nacional de Informações
}

Fabiana de Oliveira Andrade*

\begin{abstract}
Resumo: Com o avanço do regime militar, o governo sentiu a necessidade de estabelecer uma Doutrina Nacional de Informações e de oferecer uma melhor formação teórica e prática aos agentes integrantes do Sistema Nacional de Informações. Este texto abordará o processo de criação e implementação da Escola Nacional de Informações (EsNI), que esteve, desde o momento de sua criação, atrelada a tais objetivos. O trabalho contextualizará a criação da EsNI e esclarecerá as principais finalidades programadas para a Escola, tais como a formatação de uma doutrina de informações brasileiras e a capacitação de um quadro de funcionários especializados para a atividade de informações no Brasil à época. Serão elucidados, ademais, os cursos regulares e extraordinários ministrados e os materiais utilizados e publicados, como as sínteses de aula e as apostilas dos referidos cursos.

Palavras-chave: Escola Nacional de Informações, Doutrina de Segurança Nacional, Serviço Nacional de Informações.
\end{abstract}

Abstract: With the advancement of military rule, the government felt the need to establish a National Doctrine of Information and providing a better theoretical and practical training to the members agents of the National Information System. This article will discuss the process of creating and implementing the National Information School (NIS), which was from the moment of its creation, tied to such goals. The work will contextualize the creation of NIS and clarify the main aims scheduled for the School, such as formatting a doctrine of brazilian information and the training of a cadre of skilled staff for the information activity in Brazil at the time. Will, moreover, elucidated the regular and extraordinary courses and materials used and published as summaries of tuition and textbooks for these courses.

Keywords: National Information School, National Security Doctrine, National Intelligence Service.

\section{Escola Nacional de Informações: uma solução para o sistema de segurança no regime autoritário}

As dificuldades para definir a criação de uma Escola destinada à formação dos responsáveis pela atividade de informações no Brasil foram imensas. O país carecia de uma tradição voltada à capacitação do quadro de funcionários desta área e tampouco tinha experiência na elaboração de uma doutrina de informações.

*Graduada em História pela Faculdade de Ciências Humanas e Sociais da Universidade Estadual Paulista e mestranda pelo programa de pós-graduação em História pela mesma instituição, com auxílio de fomento pela CNPq. E-mail para contato: oliveirafabiana410@ hotmail.com 
Após o golpe militar de 1964, a atividade de informação teve uma formação frágil sendo sua estruturação, montagem e capacitação delegada à Golbery do Couto e Silva. A fragilidade remetia a uma espécie de amadorismo nesta área, impressão esta que não passou despercebida pelas principais autoridades da área. O General Carlos Alberto Fontoura, chefe do Serviço Nacional de Informações entre os anos de 1969 a 1974, em entrevista ao CPDOC, ressalta esta inabilidade brasileira:

Nós éramos amadores. Então tínhamos que ter uma escola que formasse agentes de informações. Esse foi o objetivo principal da [EsNI] (...). Era uma escola completa, com tudo de bom que as outras tinham. (...) Foi muito bem-feita, muito bem construída, e foi muito elogiada por chefes de serviços de informações estrangeiros que a visitaram como uma das melhores do mundo. (D’ARAUJO, 1994:71).

Após o diagnóstico das dificuldades e inabilidade dos brasileiros na área, os percalços da atividade de repressão e informações durante a década de 1964 e a evolução do regime militar, foi sentida a necessidade de profissionalização. Com isso, foi criada a Escola Nacional de Informações e elaborada a doutrina de informações brasileira, baseada no Plano Nacional de Informações.

Desde que surgiu o SNI, oriundo do antigo SFICI, a cada dia vinha se acentuando a necessidade de articular os órgãos de Informações, estabelecendo entre eles a necessária coordenação e hierarquia técnica. Sentia-se falta de consolidação de fluxos adequados de entendimento, representados por canais fidedignos e por uma linguagem comum.

o Plano Nacional de Informações estabeleceu os canais e suas regras de exploração, mas, então, sentiu-se, de maneira aguda, a necessidade de uma linguagem comum, fruto de pessoal qualificado, adestrado nos mesmos princípios e técnicas. Daí a idéia da criação de uma Escola Nacional de Informações, que já era freqüentemente cogitada, tomou corpo e originou a Exposição de Motivos $n^{\circ}$ 02, de 08 de fevereiro de 1971, do chefe do SNI, Gen. Carlos Alberto da Fontoura, propondo a criação de um Grupo de Trabalho com a finalidade de apresentar, no prazo de 60 dias, proposta de sua organização. (OLIVEIRA, 1995: 55).

Em meados do governo Médici, no dia 31 de março de 1971, o decreto ${ }^{\circ}$ 68.448/71 instituiu a criação da Escola Nacional de Informações - EsNI. Ayrton Baffa, Lúcio Sérgio Porto Oliveira e o general Ênio dos Santos Pinheiro, militar responsável pela estruturação e formação da Escola Nacional de Informações, sendo seu primeiro a ocupar o cargo de diretor nesta instituição, ressaltam as incumbências iniciais da Escola, cujos principais objetivos consistiam na cooperação com o desenvolvimento da Doutrina Nacional de Informações e na 
formação de agentes. Ademais, fazia-se urgente o estudo sobre a própria atividade de informações, a fim de que se obtivesse um melhor rendimento nas atividades do Sistema Nacional de Informações - SISNI.

O general Ênio dos Santos Pinheiro relata o momento em que foi responsabilizado pela criação da EsNI:

O presidente então me chamou e disse que havia me escolhido para construir e instalar a Escola Nacional. Eu saí general no dia 30 de março de 1971, e a idéia do presidente era que eu inaugurasse a Escola no ano seguinte, em março de 1972. Na primeira reunião que fizemos, já dispúnhamos de todas as instruções para seu planejamento - as condições tinham de ser fixadas antes de começar a discutir o problema. (D'ARAUJO, 1994:133).

Através de uma abordagem acadêmica, mas indicando razões idênticas, Joanisval Brito Gonçalves indica que, a doutrina de informações era mais do que apenas uma incumbência para a Escola. Configurada como um dos pilares da criação da EsNI, ela deveria ser conhecida e empregada por todos os órgãos do Sistema Nacional de Informações (SISNI) e por seus agentes - civis e militares. Devido à ausência de especialização do quadro de funcionários, essa iniciativa deveria estar voltada, também, à capacitação dos agentes, pois

Um serviço de informações eficiente e eficaz não seria alcançado sem profissionalização, a qual não poderia dispensar o devido treinamento e a formação doutrinária daqueles que deveriam exercer a atividade ou mesmo dos que se beneficiariam dela. (GONÇALVES, 2008: 509)

Sendo assim, o decreto $n^{\circ} 68.448$ de 1971, além de indicar a subordinação da Escola ao Chefe do SNI, estabeleceu as finalidades da EsNI em seu artigo $2^{\circ}$, em que é possível delimitá-las na preparação de civis e militares para atender as necessidades de informações e contrainformações do SISNI, na cooperação com o desenvolvimento da doutrina nacional de informações e, por fim, na realização de pesquisas visando o aperfeiçoamento das atividades do SISNI.

O decreto também ressalta a necessidade de que seu diretor fosse um general da ativa das Forças Armadas, do posto de General-de Brigada ou equivalente. Portanto, este cargo, necessariamente, deveria pertencer a um militar, indo de encontro com a afirmação de seu primeiro diretor, o general Ênio Pinheiro dos Santos, que defendia que a atuação na formação 
de agentes deveria ser predominantemente civil. Abordando sobre as condições fixadas para a construção da Escola, seu primeiro diretor indica:

Primeiro, a Escola deveria ser em Brasília. E também tinha que ser eclética, fazer a integração entre civis e militares. Então, fomos buscar especialização nos lugares em que havia militar e civil juntos. Por exemplo, eu fui para os Estados Unidos. O serviço de informações dos Estados Unidos, a CIA, é civil, o FBI é civil. Mas eles não trabalham sozinhos, de jeito nenhum. As Forças Armadas têm um grupo separado para trabalhar com esses dois órgãos: são os adidos militares. O chefe da CIA nunca comandou. Só o adido militar. Veio ao Brasil, foi ao mundo inteiro. Era um especialista. Porque é preciso aproveitar o indivíduo. (D'ARAÚJO, 1994: 133)

Já era nítida a carência de uma doutrina de informações na comunidade de informações no Brasil. As maiores contribuições obtidas a respeito provinham da tradução de obras clássicas de Sherman Kent, analista de Inteligência no Office of Strategic Services e no Office of National Estimates (CIA), foi também pioneiro no estabelecimento de métodos para a análise de informações e de Washington Platt.

Entretanto, o que mais aproximava a comunidade de informações à realidade brasileira foram escritos da Escola Superior de Guerra, principalmente ao que se relaciona com a Doutrina de Segurança Nacional, além de informações herdadas do antigo Serviço Federal de Informações e Contra-informações (SFICI). (FIGUEIREDO: 2005).

Desta forma, fazia-se urgente a formulação de uma doutrina única e empregada por todos os órgãos do SISNI, cuja prerrogativa inicial, de acordo com o Plano Nacional de Informações, seria a criação de uma Escola.

O desenvolvimento posterior do SISNI, baseado na produção doutrinária, levaria em conta uma base comum teórica e metodológica, além de contar com um treinamento prático, alcançado com os cursos fornecidos pela EsNI. Tais cursos deveriam seguir os procedimentos exigidos pelos Planos Gerais de Ensino (PGE), anuais, continuados, que regulavam as atividades de ensino e de doutrina a partir do funcionamento da EsNI.

De forma a padronizar e instruir as ações do SISNI foi editado o primeiro Manual de Informações (M-07), aprovado em 10 de dezembro de 1976 através da Portaria no 626 GAB/SNI. Este manual, portanto, consolidou e sistematizou a doutrina que já era utilizada em caráter experimental desde a edição do Manual de Informações Provisório em 1973. Priscila 
Brandão Antunes chama atenção para o Manual, que continha toda a base da doutrina de informações, sendo considerado o ancoramento das ações do SISNI.

A partir de uma edição provisória, de 1973, a Portaria $n^{\circ} 626$ - GAB/SNI, de 10 de dezembro de 1976 aprovava o Manual de Informações, o qual consolidava a doutrina e nortearia a atividade no Brasil. O Manual, documento de caráter reservado, dividia-se em Informações, ContraInformações e Operações (este último em volume separado e acessível a muito poucos), e passaria por algumas revisões, a última delas em 1989. (ANTUNES, 2002: 64)

O Manual de Informações, considerado um guia da comunidade de informações brasileira, articulava dados desde questões básicas do cotidiano de uma agência de informações, até aspectos mais específicos da atividade de coleta e análise de informações. Portanto, é possível apreender que a doutrina, na verdade, era transposta e compreendida a partir deste manual. No trecho a seguir, Lúcio Sérgio Porto Oliveira apresenta um dos aspectos tratados pelo Manual, que trata sobre a finalidade da atividade de informações, tal como extraído do M-07:

As atividades de Informações têm por finalidade a produção de
conhecimentos que habilitem as autoridades governamentais, nos
respectivos níveis e áreas de atribuição, à oportuna tomada de decisões ou a
elaborações de planos. Em sua maior amplitude, destinam-se a fornecer
subsídios ao Governo para a formulação, a execução e o acompanhamento
da Política Nacional. (OLIVEIRA, 1999: 60).

A partir deste momento, a EsNI implantou uma política de capacitação dos recursos humanos, tendo por base um trabalho técnico de definição de perfil profissiográficos que seriam encaminhados para as funções de Analista de Informações e para fazer parte das operações. Este processo teve o ápice de seu desenvolvimento com o general Otávio Aguiar de Medeiros, diretor da EsNI entre 1975 e 1978, e só pôde ser alcançado satisfatoriamente a partir do suporte técnico de um quadro de psicológicos que integrava a Divisão de Psicologia do Departamento de Doutrina e Pesquisa da Escola. (OLIVEIRA, 1999: 60).

Com o embasamento teórico adquirido através da sistematização da Doutrina de Informações e pelo Manual de Informações, adicionada à capacitação possibilitada pela EsNI, o Sistema Nacional de Informações operou mais uniformemente, de maneira sistematizada e coordenada durante as décadas de 1970 e 1980.

É possível entrever, desta forma, o papel da Escola Nacional de Informações como capacitadora dos agentes de informações, não apenas do SNI, mas da Marinha, da 
Aeronáutica, do Exército e de outros órgãos da Administração Pública, difundindo entre estes a doutrina de informações brasileira, e formando, de fato, a comunidade de informações brasileira.

Segundo o relato do primeiro diretor da EsNI, o General-de-Brigada Ênio dos Santos Pinheiro, a sede da escola seria situada em Brasília, "porque tinha que ser em Brasília" contrapondo-se à ESG e demais Escolas de Estado-Maior das Forças que se encontram no Rio de Janeiro. Isto derivava do fato de a EsNI ser encarada como o elo de integração entre civis e militares, devendo, portanto, ser eclética quanto a sua localização e seu público. Era nítido que o governo desejava construir física e ideologicamente a EsNI com distinção em relação às outras escolas. Ademais, Brasília era a nova capital do Brasil e desde tempos anteriores à Juscelino Kubitschek, era considerado um local seguro contra possíveis invasões externas e conflitos internos devido à sua localização geográfica no Planalto Central do Brasil. Portanto, foi conveniente a instalação da Escola Nacional de Informações na nova capital que também necessitava da centralização de suas principais atividades.

A partir da criação da Escola Nacional de Informações, a primeira dificuldade apresentada referia-se ao local de instalação e montagem da EsNI, como é comentado por Oliveira. Em Brasília, havia a previsão de três distintos locais:

1. A primeira, em área próxima ao Regimento de Cavalaria de Guardas RCG, nas imediações do Parque Ferroviário;

2. A segunda, nas proximidades do Grupo de Artilharia Antiaérea GAAAe, no Setor Militar Urbano, denominada área do Canil; $e$

3. A terceira, na margem esquerda da estrada que liga o Setor Policial Sul a Taguatinga, por detrás da área da Polícia Militar do Distrito Federal. (OLIVEIRA, 1999: 57)

O documento oficial aponta as razões pelas quais a última opção foi a mais conveniente para a instalação da Escola. Evidentemente, a instalação da EsNI próximo ao Setor Policial já indicava a natureza que a nortearia. As justificativas oficiais apontam:

"e. 1. A área está desimpedida, não havendo nenhum processo em andamento para instalação de qualquer órgão.

e. 2. A EsNI poderá obter toda a área disponível para maior segurança física.

e. 3. A Coordenação de Arquitetura e Urbanismo, através de sua Chefia, apresentou inconveniência na liberação das áreas do RCG e do Canil (onde ficam Hospitais especializados), mas sugeriu a área do Setor Policial. 
e.4. A área é plana, de fácil acesso e bem enquadrada com relação aos prováveis setores residenciais. (CRUZEIRO NOVO e SQS 311)". (OLIVEIRA: 57-58)

A Escola Nacional de Informações estabeleceu-se em um conjunto arquitetônico que se adequavam aos princípios da atividade de inteligência. Inicialmente, pensou-se em edificar a Escola em um prédio único com vários pavimentos, porém, por questões de segurança e de confiabilidade, a obra foi feita em vários blocos separados, obedecendo ao quesito básico da inteligência: a compartimentação de informações. Desta forma, as atividades desenvolvidas em determinada estrutura não seriam conhecidas por outras estruturas, e vice-versa. Destarte, a instalação em um terreno amplo permitia certa flexibilidade para estender sua capacidade e utilizar novas formas de atuação dentro do campo do ensino.

O general Ênio dos Santos Pinheiro, ao relatar a sua inserção na criação da EsNI, explicita como se iniciou seu processo de elaboração:

E o que aconteceu? Pensei comigo: "O que vou fazer? Esse troço é secreto". Chamei o capitão Fortuna, que tinha trabalhado comigo no Batalhão Ferroviário, engenheiro formado no IME. Ele topou [...]. Eu o levei comigo, dei-lhe casa, dei-lhe tudo; E ele projetou a Escola todinha. Eu ia desenhando: "Quero a Escola assim, assado". E a Novacap construía. Houve dificuldades, porque a Novacap teve que penetrar, conhecer, para saber o que ia fazer. E tínhamos um stand de tiro subterrâneo, uma porção de coisas. Foi um pouco complicado. (D'ARAÚJO, 1994: 134)

Após percorrer serviços de excelência no mundo ocidental capitalista, os responsáveis pela montagem da EsNI a equiparam com um dos melhores laboratórios de línguas do Brasil ${ }^{1}$, os mais modernos aparelhos eletrônicos, e também uma academia sofisticada de tiro subterrânea $^{2}$, contendo isolamento sonoro e cabines separadas por vidros blindados. Além disso, havia um auditório cujos assentos possuíam fones de ouvido individuais, com flexibilidade para se transformar em uma sala de cinema - a melhor de Brasília - e um estúdio de televisão.

A construção da EsNI teve grande apoio dos serviços congêneres, principalmente norte-americanos, que forneceram cursos e treinamentos tanto ao general Ênio dos Santos Pinheiro, quanto aos membros que integrariam a EsNI.

\footnotetext{
${ }^{1}$ A notoriedade do curso de idiomas da EsNI foi tão grande que seu laboratório de idiomas foi considerado o melhor da América Latina e significativamente pareado com os de outros serviços de informações dos países desenvolvidos.

${ }^{2} \mathrm{~A}$ montagem desse estande de tiros foi a maior dificuldade encontrada pela empresa responsável pela construção, a Novacap.
} 
Os americanos perceberam que nosso projeto era para valer e se interessaram [...] porque nossos princípios eram os mesmos, a parte teórica era parecida com a americana. Nós não tínhamos, por exemplo, equipamento. Agora, as nossas instalações eram muito melhores que as deles $[. .$.$] .$

Quando a Escola começou a ser construída, os americanos ofereceram ao general Médici um curso de seis meses para mim na CIA e no FBI, para trazer a documentação que eles empregavam nos Estados Unidos e criar os regulamentos. Então fui para Washington fazer esse curso [...] Ficamos num hotel [...] eles o escolheram porque havia um subterrâneo que permitia que entrassem por baixo do edifício diretamente onde nós estávamos. E era no hotel mesmo que tínhamos aula. Todos os dias de manhã, os professores iam lá com os aparelhos. Nós não podíamos sair [...] Ficamos lá um bocado de tempo e, afinal, trouxemos toda a documentação. (D’ARAÚUO, 1994: 133134)

Ainda hoje a estrutura da Escola ganha destaque, pois a Escola de Inteligência (ESINT) da Agência Brasileira de Inteligência (ABIN) continua funcionando no local, que contém, além do estande de tiro, vários blocos e uma estrutura completa para a prática desportiva - piscinas olímpicas, quadras de futebol, pistas de atletismos e até um ginásio coberto.

Inúmeras vezes a temática da instalação da EsNI é citada pelo General Ênio Pinheiro dos Santos, seja em entrevista cedida ao CPDOC, seja na oportunidade de transmissão do cargo da diretoria da Escola ao seu sucessor, em 1974.

Oliveira transcreve em sua obra, que demonstra a história dos serviços de informações destinada à ABIN, o discurso do momento em que o General Ênio Pinheiro dos Santos transfere seu cargo ao sucessor General José Albuquerque, em 14 de agosto de 1974:

A hora da partida é um momento de pesar, mas pode, também, ser um momento de alegria. É um momento de pesar, porque as pessoas e as coisas que se fizeram caras para os nossos corações vão se tornando distantes e intangiveis. Pode ser um momento de alegria, porque permite-nos parar e olhar para trás e vermos tudo que foi realizado, os amigos que fizemos, as coisas que construímos, o bem que realizamos. Neste instante, olhando para trás sentimo-nos tranqüilos, porque parece-nos que não falhamos que não desmerecemos da confiança em nós depositada pelo Exm ${ }^{\circ}$ Sr. Presidente da República e Exm ${ }^{\circ}$ Sr. Ministro Chefe do Serviço Nacional de Informações. Mercê de Deus a tarefa que recebemos foi integralmente cumprida construir e implantar a ESCOLA NACIONAL DE INFORMAÇÕES. Todos os edifícios projetados foram construídos e a Escola está com todos os seus cursos em funcionamento.

Para obtermos os resultados alcançados foi decisiva a dedicação excepcional da brilhante equipe que consegui formar. Toda a equipe que constitui o Corpo Permanente da Escola agiu como um bloco monolítico, 
sem medir sacrificios e canseiras, para que os objetivos fixados fossem colimados e a Escola atingisse o alto padrão que já atingiu.

Dentro desta brilhante equipe devemos, indubitavelmente, incluir os engenheiros e trabalhadores da NOVACAP que tudo fizeram para atender os apertados prazos que haviam sido estabelecidos para as várias fases de construção da Escola, e que nunca falharam dirigida pela excepcional figura de engenheiro que é o jovem Dr. MÁRIO LÚClO DE SOUZA BASTOS.

Neste momento de despedida, todos devemos estar orgulhosos, tranqüilos e confiantes, pois, juntos, conseguimos realizar uma obra importante para o nosso País, que irá revolucionar o ensino e a produção das Informações do BRASIL.

É evidente que a obra não está acabada e requer cuidados especiais para crescer forte e sadia. Mas, o marco que implantamos foi o mais difícil e está sólido, permitindo uma tranqüila evolução da Escola no sentido de seu aperfeiçoamento. (OLIVEIRA, 1999: 58)

A estrutura funcional da EsNI, basicamente, compreendia a Direção e o Departamento de Ensino, responsável pela organização e execução dos cursos básicos (A, B e C) e dos estágios, variáveis em cada ano, para atendimento de informações circunstanciais. Este departamento possuía também uma Divisão de Pedagogia, cuja responsabilidade era planejar e controlar o ensino da Escola.

Além deste departamento, constava também o Departamento de Pesquisa e Doutrina, que, além do indicado em sua nomenclatura, também era responsável pela Divisão de Idioma e pela Divisão de Psicologia. Através deste departamento, foram editadas diversas publicações doutrinárias, com destaque às revistas Coletânea L e Inteligência ${ }^{3}$. Desta forma, o grande diferencial da Escola era a preocupação constante não somente com a teorização e prática das disciplinas de informações, mas também com a metodologia e didática empregadas. A EsNI era responsável, ademais, pela elaboração de pesquisas e formulação da Doutrina de Informações, o que atribuiu um grau de excelência para a Escola.

O Departamento de Administração, por sua vez, contemplava grande número de funcionários, em maioria civil, qualificados para suas atribuições. Oliveira descreve o perfil, competência e prestatividade dos profissionais que eles acreditavam ter em seus quadros: "acendrado espírito de corpo, sadio em todos os sentidos, e comprovado pelo modo como eram atendidos, por mais complexos que fossem os pedidos e as ordens atribuídos à Escola, sempre cumpridos com presteza, correção e dedicação". (OLIVEIRA, 1999: 64)

\footnotetext{
${ }^{3}$ Tais publicações influenciaram fortemente a evolução e a consolidação da doutrina nacional de Inteligência no Brasil, uma vez que foi veículo difusor de inúmeros temas relativos à atividade de informações no Brasil e no mundo.
} 
Ademais, ressalta-se o Departamento de Informática do Serviço Nacional de Informações, que permanecia sob controle estritamente administrativo da EsNI, conforme ressalva Oliveira, e o Centro de Pesquisas, destinado a análise de criptografia e fornecimento de equipamentos criptográficos, sendo o antecessor do Centro de Pesquisas e Desenvolvimento para a Segurança das Comunicações - CEPESC.

O corpo docente foi dimensionado visando atender às necessidades do ensino a que se propunha a Escola Nacional de Informações - entre estas, a elaboração da doutrina de informações. A preferência na escolha da equipe de instrutores da Escola era por pessoas com alguma experiência na área de informações, embora o general Ênio dos Santos Pinheiro demonstrasse a intenção de mesclar militares e civis - até então considerados despreparados devido a sua longa ausência dos bancos formadores da área de informações - dentro do quadro de funcionários.

Fomos pegando as pessoas que tinham função de informação, que já possuíam vivência nesse assunto [...] Desde o princípio tivemos a preocupação de colocar alguns civis, além do pessoal do Exército, da Marinha e da FAB. Esse era o núcleo central da Escola. [...].

Para entrar na Escola, era preciso fazer exame psicotécnico, psicológico, porque nós queríamos conhecer o perfil do homem brasileiro de informações, que não era o mesmo do americano. (D'ARAÚJO, 1994: 136)

Foram selecionados alguns oficiais das Forças Armadas, para a composição do corpo docente, a fim de serem enviados ao exterior para frequentarem cursos e aulas em outras escolas e serviços de informações aliados, para que passassem a conhecer a estrutura e o funcionamento de outros serviços e de seus programas de formação. Segundo relata o General Ênio Santos Pinheiro, em suas memórias para o livro do CPDOC (OLIVEIRA, 1999: 135), os principais países intercambistas foram os Estados Unidos, Alemanha Ocidental, Israel, França e Grã-Bretanha. De forma a completar o quadro docente, Gonçalves indica que, além dos professores, era constituído por montares ${ }^{4}$ preparados e versáteis, geralmente mais jovens, que ministravam aulas mais didáticas e intelectualizadas. Complementarmente a estes oficiais, integrou o corpo docente da Escola os funcionários da Escola Superior de Guerra e das Forças Armadas, outrora responsáveis pela formação dos agentes de informações, e também alguns profissionais do próprio Serviço Nacional de Informações.

\footnotetext{
${ }^{4}$ Segundo tradição oral, Montares remete à jovens oficiais. Entretanto, dicionários consultados não apresentam o verbete, embora tenha sido empregado na tese de doutorado de Joanisval Brito Golçalves, fonte relevante para esta etapa da pesquisa.
} 
Destarte, além de instrutores permanentes e externos, a Escola também contava com uma equipe de pedagogos, professores de idiomas, tradutores, e técnicos e psicológicos, formando uma equipe de funcionários altamente qualificada.

Paralelamente à formação do corpo docente, a equipe discente foi composta, nos cursos A, B e C, em grande parte, por funcionários públicos, ligados ao SISNI e por militares das três Forças. (OLIVEIRA, 1999) A política de pessoal, neste momento, trabalhava no perfil profissiográficos dos aspirantes à Escola, destinando-os, após essas análises, às funções de análise de informações ou às operações. Para tanto, contava com o apoio da Divisão de Psicologia do Departamento de Doutrina e Pesquisa que oferecia um quadro de psicólogos especializados que avaliavam cada perfil individualmente.

Para o ingresso na escola, era necessária a realização de exames psicotécnico e psicológico, para que se estabelecesse o perfil do homem brasileiro integrante do sistema de informações. Quando questionado, o General Ênio Santos Pinheiro discute dois tipos de pessoas admitidas na Escola: "um, intelectual, e outro, que trabalhava no campo de operações", após a seleção era "feito um código de honra e um código de ética para o pessoal" (D’ARAÚJO, 1994: 136). Ainda nesta coletânea, o general Ênio dos Santos Pinheiro atribui a formação dos agentes do Serviço Nacional de Informações e do Sistema Nacional de Informações, durante o período anterior à inauguração da Escola Nacional de Informações, às academias militares, tendo em vista o combate à subversão.

Os futuros alunos da Escola eram indicados pelo comandante de suas unidades militares, e sua faixa etária abrangia entre 21 e 24 anos. Eles deveriam ter cumprido o serviço militar obrigatório em corpos de elite do Exército, além de ainda ocuparem, nas Forças Armadas, o posto de segundos-tenentes. Posteriormente, havia uma rigorosa seleção que incluía investigação social, exames médicos na Policlínica da Aeronáutica e psicotécnico. Após aprovados, Lucas Figueiredo indica que os candidatos eram convidados a abandonar seus postos nas Forças Armadas e cursar a Escola, entretanto, o curso de informação na EsNI não garantia efetivamente um emprego no SISNI ou no SNI. Além dessas características o futuro analista "deve possuir raciocínio lógico apreciável, percepção e objetividade, assim como conhecimentos concernentes às atividades de Informações, e às necessidades de Informações dos Órgãos Governamentais, a fim de capacitá-lo a realizar essas atividades mentais com sucesso" 5 .

${ }^{5}$ NA-BC-07-203 - Reservado - EsNI, 1972. 
A EsNI foi incumbida de dar conta, não somente da formação de militares, mas principalmente civis que integrariam o SISNI e o SNI, afinal este era um órgão moldado na CIA, e portanto, de caráter civil. Desta forma, a grande maioria dos alunos que integrou o quadro discente da EsNI era civil, selecionados entre os funcionários dos ministérios, de empresas públicas e autarquias, em sua maioria jovens, que se interessassem ou tivessem aptidão para trilhar a carreira na área de informações e inteligência.

Carlos Alberto da Fontoura, dirigente do SNI entre 1969 e 1974, embora representasse parte do contingente militar que dirigia a Escola, que tinha em seus moldes de ensino um modelo de instrução militar, ressalta a importância da formação de um sistema civil:

A minha política era a seguinte: vão freqüentar essa Escola, preferencialmente civis. O SNI é um órgão civil, e deve passar às mãos dos civis no mais curto prazo possivel, inclusive a chefia. Claro que isso dependeria do Presidente da República. Mas a minha política era essa. Matriculei muito poucos militares durante o tempo em que estive no SNI [1969-1974]. Praticamente só civis pessoal indicado por Ministérios, por diferentes órgãos. É claro que sofriam um rastreamento, e mesmo lá dentro eram muito bem observados. (D’ARAÚJO, 1994: 94)

Entretanto, na década de 1970, ingressaram na Escola alguns jovens oriundos do Núcleo de Preparação dos Oficiais da Reserva e do Centro de Preparação dos Oficiais da Reserva, os chamados “oficiais R2". Estes eram selecionados em suas unidades militares e, para se matricularem na Escola e realizarem seus cursos, deveriam se desincorporar do serviço militar. A maioria dos jovens tinha curso superior completo ou incompleto e acabaram por integrar o quadro de funcionários do SNI da década de 1980 até 1990 . Tendo em vista a influência de tal categoria de oficiais, os postos chaves ocupados na $\mathrm{ABIN}^{6}$ provêm destes analistas de carreiras, salvo, raras vezes, os concursados.

\section{Os cursos de informações a partir de 1972: a criação da Escola Nacional de Informações e a evolução formativa dos pretensos agentes.}

O general Ênio Pinheiro informa que além do funcionamento do curso de idiomas, também eram oferecidos cursos permeados por uma doutrina anticomunista, divididos em três categorias: A) Altos Estudos, com duração de um ano letivo; B) Fundamentos; e C)

\footnotetext{
${ }^{6}$ Márcio Paulo Buzanelli, Diretor-Geral da ABIN entre os anos 2005 e 2007, fazia parte dos oficiais R2.
} 
Operações. Os dois últimos com duração de um semestre. Todos tinham aula de segunda à sexta-feira, em período integral, contando com turmas de, no máximo, trinta alunos. Formando, portanto, cerca de 120 pessoas por ano. (D’ARAÚJO, 1994).

A legislação que instituiu a criação da Escola Nacional de Informações, em seu artigo $5^{\circ}$ trata dos cursos e estágios os quais passariam a ser de responsabilidade da EsNI:

Art. $5^{\circ}$ Os Cursos e Estágios relacionados com as atividades de Informações do Sistema Nacional de Informações, em funcionamento em outras Escolas ou entidades de ensino, serão absorvidos pela Escola Nacional de Informações (EsNI), à medida que forem sendo ativados os seus Cursos ou Estágios considerados equivalentes. ${ }^{7}$

À vista disso, a EsNI cumpriu seu objetivo de centralizar a formação da atividade de informações no Brasil ( GONÇALVES, 2008). Para tanto, a Escola recebeu o Curso de Informações $^{8}$ - que integraria o curso categoria "A" - da Escola Superior de Guerra . (OLIVEIRA, 1999) Destinado à formação e habilitação de analistas de informações em âmbito nacional, o curso "A" era voltado para a formação de chefias, sendo como uma pósgraduação, já que se exigia que o aluno-estagiário fosse formado no curso "B" ou "C". Isto posto, para o grupo civil, era requerido o título de formação universitária ou, no caso de militares, deveriam ser oficiais das Forças Armadas, ocupantes de postos de Oficial Superior, sendo formados no Curso de Comando e Estado-Maior.

As aulas versavam sobre assuntos políticos, econômicos e sociais da realidade brasileira, tendo em vista a análise de conjuntura e estudo de casos. O Planejamento da EsNI de 1987 complementa: “em seus cursos básicos, será transmitido o conhecimento genérico a conjuntura interna e externa, nos campos político, econômico e psicossocial, com ênfase para os aspectos relacionados com a Segurança Nacional" 9 .

A segunda categoria de cursos, "B", era destinada à formação de Analistas de Informações, que foi assimilado do Curso de Informações do Centro de Estudos do Pessoal do Exército $-\mathrm{CEP}^{10} \mathrm{e}$ a formação dos analistas de informações destinava-se ao âmbito regional e setorial. Para o corpo discente requeria-se oficiais das Forças Armadas que fossem detentores de postos de capitão e major, e civis com curso universitário completo (OLIVEIRA, 1999).

\footnotetext{
${ }^{7}$ Decreto $\mathrm{N}^{\circ}$ 68.448, de 31 de março de 1971. Consultado em http://legis.senado.gov.br/legislacao/ListaPublicacoes.action?id=198597 no dia 29 de março de 2013.

${ }^{8} \mathrm{O}$ Curso de Informações da ESG havia sido instituído mediante o Decreto $\mathrm{n}^{\circ} 55.791$, de 23 de fevereiro de 1965, "com a finalidade de cooperar no estudo e desenvolvimento de uma doutrina de Segurança Nacional e preparar civis e militares para funções relacionadas com as Informações".

${ }^{9}$ Diretriz para o Planejamento do Ano Letivo da EsNI em 1987. Material fornecido pelo Arquivo Nacional-DF

${ }^{10}$ Tanto o Curso da ESG quanto o do CEP, ao serem transferidos para a Escola Nacional de Informações, foram desativados em suas escolas de origem.
} 
O curso abordava disciplinas como sociologia, história, geografia e ciências políticas. Inicialmente, o aluno estudava a história do comunismo, desde o surgimento da doutrina, com Karl Marx, perpassando pela Revolução Russa, em 1917, e finalizando com a Revolução Cubana e seus efeitos na América Latina. Podemos analisar o processo da Guerra Revolucionária como pode ser encontrado nas sínteses para aulas encontradas no Arquivo Nacional em Brasília ${ }^{11}$.

À terceira modalidade de cursos - categoria "C"- cabia a responsabilidade pelo campo prático da atividade de informações e contava com um processo de seleção mais rígido, pois seu objetivo era a formação dos "agentes de rua" do SNI, a atividade mais perigosa e delicada. Destarte, os Cursos de Operações de Informações, titulados Cursos C1 e C2 ${ }^{12}$, eram destinados à preparação de pessoas para a coleta de informações e dados.

Para integrarem o corpo discente do Curso C-1 demandava-se que fossem de organizações distintas das Forças Armadas e, no caso de civis, também deveriam portar nível superior. Já o Curso C-2 era integrado por praças - especialmente suboficiais e sargentos - das Forças Armadas e civis com o nível médio de escolaridade.

Ao longo da trajetória histórica que marcou a EsNI, foram realizados diversos cursos, programas de treinamento, estágios e eventos especiais - seminários e painéis, visando sempre ao aprimoramento do grau de especialização dos agentes e da doutrina nacional de Informações. Portanto, além dos cursos regulares, a EsNI oferecia os denominados "cursos extraordinários", ministrados para adidos militares e funcionários públicos que trabalhavam com informações estratégicas.

No caso dos adidos militares, e também das pessoas que, embora no exterior, tivessem contato com informações, a EsNI também oferecia um curso, contendo, inclusive, programas de total imersão idiomática.

Destinado aos Ministros de Estado, outro programa especial contou com uma carga horária de 48 horas. Segundo o general Ênio Pinheiro, todos os ministros deveriam fazer esse curso, embora separados, para lhes ensinar o que era informação, como usar essas informações que lhes eram repassados, sua utilidade e importância.

Outro curso que merece destaque é o Curso de Analista da Área Econômica, ministrado de 2 de fevereiro a 23 de julho de 1981, e os Cursos de Informações do Campo Externo, realizado do dia $1^{\circ}$ de março de 1982 a 8 de dezembro de 1989 . Foram realizados

\footnotetext{
${ }^{11}$ Posteriormente, serão discutidas com maior precisão as matérias e temas debatidos nos referidos cursos.

${ }^{12}$ Os cursos categoria "A", "B" e "C" foram regulados pelo primeiro Regulamento da EsNI, baixado em 1972, diploma que também contemplava os demais programas de ensino, denominados Estágios.
} 
também os Estágios de Proteção da Informação Empresarial Sensível - EsPIE entre os anos de 1985 a 1987.

Entre os cursos extraordinários e programas especiais que constam nos currículos da EsNI, tem-se também como exemplo os Estágios de Criptologia, Análise de Propaganda, Estimativa, Recrutamento e Entrevista.

O curso de aperfeiçoamento de analistas foi oriundo da interação entre a Agência Central (AC) do SNI e a EsNI. Segundo as necessidades, a Agência Central defendia a necessidade de uma especialização de seus analistas e, de outro, a EsNI foi projetada para atender essa finalidade, estando apta a assumir, em termos de ensino, tal responsabilidade. Desta forma, era permitido a EsNI, a cada ano letivo, executar um curso destinado à determinada especialidade.

Cada curso de aperfeiçoamento continha dois módulos, sendo o primeiro à distância, através da correspondência, e o segundo presencial, cujos alunos se reuniriam na Escola. Ambas as fases correspondiam à carência pela qual passaria o SNI caso a maioria de seus analistas fossem afastados de seus cargos e deveres, em suas agências, por um tempo prolongado.

O grande desafio da EsNI foi o desenvolvimento de um curso à distância eficaz e qualitativo. Para tanto, contou-se, especialmente, com a Divisão de Pedagogia para a organização do Curso de Analistas do Campo Econômico ${ }^{13}$, o primeiro e único Curso de Aperfeiçoamento de Analistas realizado pela EsNI.

O ensino à distância, onde a EsNI foi pioneira, baseava-se na elaboração de apostilas por professores selecionados da Universidade de Brasília - UnB, rigorosamente elaborado em termos pedagógicos pela Divisão de Pedagogia.

As apostilas possuíam um capítulo exclusivo para uma autorreflexão sobre o tema abordado, oferecendo material e bibliografia complementar sem onerar os alunos matriculados. Além disso, a EsNI disponibilizou uma linha telefônica exclusiva para atendimento dos alunos.

Os principais objetivos do Curso de Estratégia visavam proporcionar ao pessoal da EsNI a dimensão estratégica de seus estudos e de suas análises, compatibilizando, também, o Plano Nacional de Informações (PNI) com o nível dos planejamentos político-estratégicos do Poder Executivo em esfera Federal. Também era incumbência deste Curso favorecer que a

\footnotetext{
${ }^{13}$ Este curso foi realizado em 1980.
} 
doutrina de informações sedimentasse aspectos que se referem a valores, conceitos e princípios.

Em oito meses de elaboração, o Curso de Estratégia compreendia uma organização curricular e seleção de professores e de alunos rigorosa.

A Divisão de Pedagogia da EsNI, por sua vez, elaborou uma pesquisa pedagógica, consultando tanto em esfera nacional quanto internacional, os prováveis conhecimentos que deveria ser portador um analista de estratégia para o cumprimento adequado de suas incumbências e funções.

Durante poucos anos o Curso funcionou, mesmo com o incorreto nome de Curso de Informações do Campo Externo (CICE), quando, na verdade, o campo externo era uma derivada da grande Estratégia Nacional, e o currículo assim o expressava. Mas esse óbice não ofuscou o valor do Curso, confirmado por pessoas que o fizeram e não integravam o quadro do SNI. Os analistas que freqüentaram o Curso e eram do SNI também avaliaram-no como de grande importância para o SNI. Lamentável que tenha sido interrompido sem que houvesse o tempo necessário para criar uma massa crítica de analistas com a visão estratégica das informações. (OLIVEIRA, 1999: 70).

Durante o período em que a EsNI formou os agentes para o Sistema Nacional de Informações, o número de intercâmbios para as escolas de agências de informações e inteligência em países como Estados Unidos, Alemanha, Inglaterra, entre outros foi alto, o que mostra a influência apreendida através do contato com outros países capitalistas.

Como explicitado anteriormente, o militar responsável pela montagem e estruturação da EsNI foi o general Ênio dos Santos que, convidado pelo presidente norte-americano Richard Nixon e pelo FBI, viajou, juntamente com o almirante Sérgio Doherty, a Washington no início de 1971. Através desse contato, os instrutores norte-americanos propuseram ao general Ênio Pinheiro eixos e perspectivas para a montagem de uma escola de inteligência. As orientações fornecidas pelos norte-americanos não se restringiam ao campo teórico, institucional e administrativo, os ensinamentos práticos também entravam em pauta como, por exemplo, a abordagem durante um interrogatório:

A primeira providência, ensinaram os americanos, era tirar toda a roupa do prisioneiro - um modo de evitar acidentes com objetos escondidos ou mesmo cintos e cadarços e também uma forma de humilhar o preso, quebrando sua resistência. Enquanto um interrogador fazia perguntar, outro tomava nota e um terceiro assistia a tudo numa sala contigua escondido por um espelho falso. [...] em outra aula, o general e o almirante viram como os agentes secretos americanos faziam o controle da embaixada 
russa em Washington e vigiavam os espiões de Moscou disfarçados de diplomatas. Era uma operação ultra complexa que impressionou os militares brasileiros [...] (FIGUEIREDO: 222-223)

Ao retornar ao Brasil, o general Ênio Pinheiro responsabilizou-se pela formulação do material da escola brasileira baseando-se em informações, relatórios e documentos trazidos dos Estados Unidos, sem deixar claro, como ele próprio confessa à Maria Celina d'Araújo, Gláucio Soares e Celso Castro em sua coletânea "Anos de Chumbo - memória militar sobre a repressão”, a fonte. Portanto, é nítido o embasamento teórico provindo dos materiais da CIA e do FBI permeando o primeiro material da escola de informações brasileira. O próprio entrevistado diz, ao retornar ao Brasil: "peguei todo o material e fui mostrar ao presidente para combinar a forma como iríamos empregá-lo. Dei uma pinçadas e fui fazendo os documentos brasileiros baseados nos documentos americanos, sem dizer a fonte". (D’ARAÚJO, 1994: 135).

O documento básico que regulava as atividades de ensino e doutrina integrantes da missão institucional da EsNI era os Planos Gerais de Ensino - PGE, um documento continuado e anual. Entretanto, o PGE esteve imbrincado ao primeiro Manual de Informações (M-07), já citado anteriormente.

Com o avanço do regime militar, e o Congresso cada vez mais silenciado e portador de uma postura secundária. A figura centralizadora do presidente da República abriu precedentes para que o SNI apresentasse uma postura mais autônoma, devido ao fato de o órgão estar cada vez mais vinculado à postura autoritária do governo e se mostrar cada vez mais importante para a manutenção do regime militar. Paralelamente a isto, as necessidades de informações do regime militar se intensificaram, pois não se tratava de reunir dados indispensáveis ao principal cliente do serviço - o presidente da República -, mas de interagir com a polícia política, isto é, com o sistema de segurança que naquele momento se buscava aperfeiçoar. Assim sendo, até 1967, o objetivo principal do Serviço Nacional de Informações era a coleta, análise e organização de informações. O SNI passou a se dedicar, portanto, ao estudo da política, economia e sociedade no país, deixando de ser um órgão exclusivamente voltado para a busca e análise de informações, chegando a influenciar, mesmo que de forma indireta, o sistema de repressão do governo.

Com a morte de Costa e Silva e a ascensão de Médici à presidência da República, foi sentida a necessidade do desenvolvimento e profissionalização dos agentes de informações. O governo, para tanto, previu a construção de uma escola responsável pelo aperfeiçoamento da 
atividade de informações. Para atender a tais necessidades foi criada a Escola Nacional de Informações, posta em funcionamento em 1972. Neste momento, foi possível compreender as instalações e a composição física e humana da EsNI, através de sua administração, corpo discente e docente, bem como de seus cursos

Desta forma, é possível entrever indícios, ainda que obscuros e não declarados, de que a mesma concepção presente no Serviço Nacional de Informações onde este se reveste como um órgão cujo objetivo principal se modifica está também presente na EsNI. Quando o órgão se torna um parâmetro para Costa e Silva, seu objetivo deixa de abarcar somente a coleta e a análise de informações bem como seu fornecimento ao presidente da República e passa a ser possuidor de um papel de assessoria, de formulador de ideologias e opiniões à presidência da República e a vários recônditos da sociedade. Desta forma, pode-se entender o SNI não como um mero fornecedor de informações que subsidiam as decisões do presidente, mas como um formulador dentro de um sistema de informações.

Essa visão deturpada da área de informações e da sociedade brasileira, que foi, inclusive, corroborada não somente pela formação militar fora do Brasil, mas também a formação interna, oferecida pela ESG e posteriormente pela EsNI, fez com que, muitas vezes, a rede de informações fosse alimentada com inúmeros filtros. Sendo assim, o aparato ideológico ensinado abria possibilidade para que as informações que chegavam à autoridade final - o presidente da República - tivessem passado já pela filtragem executada pelos agentes. Portanto, as informações obtidas com as prisões, técnicas de interrogatórios e elaboração de relatórios atendiam a uma determinada posição ideológica, que trabalhava a favor do governo militar e da Doutrina da Segurança Nacional.

Através da declaração de Ernesto Geisel, que demonstra a "paixão" e a subjetividade do SNI que sobrepuseram sua visão técnica dos fatos é possível concluir, principalmente tendo em vista o material da Escola, que esta paixão também esteve presente na EsNI, em seus manuais, em suas doutrinas e, principalmente, na formação de seus agentes.

\section{Referências Bibliográficas}

D’ARAUJO. Maria Celina. CASTRO, Celso(orgs). Ernesto Geisel. Rio de Janeiro: Editora Fundação Getúlio Vargas, 1997.

D’ARAUJO, Maria Celina, SOARES, Glaucio Ary Dillon, CASTRO, Celso. Os anos de chumbo: a memória militar sobre a repressão. Rio de Janeiro: Relume-Dumará, 1994.

FICO, Carlos. Como eles agem. Os subterrâneos da Ditadura Militar: espionagem e polícia política. Rio de Janeiro: Record, 2001. 
FIGUEIREDO, Lucas. Ministério do Silêncio: A história do serviço secreto brasileiro de Washington Luís a Lula, 1927-2005. Rio de Janeiro: Record, 2005.

GASPARI, Élio. A Ditadura Envergonhada. São Paulo: Companhia das Letras, 2002.

GONÇALVES, Joanisval Brito. SED QUIS CUSTODIET IPSO CUSTODES? O Controle da atividade de inteligência em regimes democráticos: os casos de Brasil e Canadá. Tese de doutorado apresentada para a Universidade de Brasília - UnB, 2008.

OLIVEIRA, Lúcio Sérgio Porto. A história da atividade de inteligência no Brasil. Brasília : ABIN, 1999.

STEPAN, Alfred. Os Militares: da Abertura à Nova República. Tradução de Adriana Lopez e Ana Luíza Amendola. Rio de Janeiro: Paz e Terra, 1996. p. 29.

\section{Fontes}

Decreto $\quad N^{\circ}$ 68.448, de 31 de março de 1971. Consultado em http://legis.senado.gov.br/legislacao/ListaPublicacoes.action?id=198597 no dia 29 de março de 2013.

Diretriz para o Planejamento do Ano Letivo da EsNI em 1987. Material fornecido pelo Arquivo Nacional-DF. Apostilas do curso modalidade "B" da EsNI:

(1972) Princípios da produção de documentos e informes

(1972) "Informações internas" -NA-B-07

(1972) "Informações externas" - NA-B-07-13

(1972) "Informações de segurança interna" - NA-B-07-14

(1972) "Segurança das comunicações" - NA-C-09-205

(1972) "Plano de busca" - TI-B-07-21

(1972) "Planejamento" - NA-BC-07-21

(1972) "Processamento de informes" - NA-BC-07-203

(1972) "Difusão" - NA-BC-07-204

(1972) "Ficha de estudo e de trabalho em domicílio" - TI-G-09-101

(1972) "Exercício de confecção de um plano de busca n 1 " - TI-B-07-21

ESTADO-MAIOR DAS FORÇAS ARMADAS. (1959), "Introdução ao estudo da guerra revolucionária", conferência de Augusto Fragoso. Rio de Janeiro, Escola Superior de Guerra. . (1969), Aspectos da guerra contemporânea: a guerra revolucionária. Rio de Janeiro, Escola Superior de Guerra, Departamento de Estudos, C-20-69. . (1961), Conceituação de Guerra Insurrecional. Rio de Janeiro.

ESTADO-MAIOR DO EXÉRCITO. (1969), O Pequeno Escalão nas Operações de Contraguerrilha. Instruções Provisórias do Ministério do Exército. 